RASĀYAN J. Chem.

Vol. 12 | No. 4 |1688 - 1692| October - December | 2019 ISSN: 0974-1496 | e-ISSN: 0976-0083 | CODEN: RJCABP

RJC http://www.rasayanjournal.com http://www.rasayanjournal.co.in

\title{
SPECTROSCOPIC, MECHANICAL AND DIELECTRIC STUDIES ON FILMS OF EPOXYRESIN IN DIETHYLENETRIAMINE
}

\author{
M.V.L. Kumari ${ }^{1,2, *}$, A. Kaviarasi ${ }^{1,2}$, A.R. Prabakaran ${ }^{2}$ and A. Anandavadivel ${ }^{3}$ \\ ${ }^{1}$ Department of Physics, Dr. M.G.R Educational and Research Institute, \\ Chennai-600 095, (Tamilnadu), India \\ ${ }^{2}$ Department of Physics, Pachaiyappa's College, Chennai-600 030, (Tamilnadu), India \\ ${ }^{3}$ Department of Physics, Sri Venkateswara College of Engineering, \\ Sriperumbudhur-600105, (Tamilnadu), India \\ *E-mail:suryajittu56@gmail.com
}

\begin{abstract}
Solvent evaporation technique is employed to cast films of cured Epoxy resin in Diethylenetriamine.Diethylenetriamine is an organic solvent. Polymer and curing agent concentration is varied in $\mathrm{wt} / \mathrm{wt}$ ratio. The FTIR studies are employed as a tool to identify the functional groups and the importance of curing agent.Samples are subjected to mechanical studies and mechanical parameters -toughness, flexural and tensile strengths are established.Dielectric studies are performedat different concentrations of curing agent.

Keywords: FTIR, Tensile Strength, Flexural Strength, Toughness, Curing Agent, Epoxy Resin, Diethylenetriamine

(C) RASĀYAN. All rights reserved
\end{abstract}

\section{INTRODUCTION}

The synthesis of materials as films is anindispensable step in many applications.Films play a crucial role in the enhancement and study of materials with new and peculiar properties. The titled compound (EP) is thesignificantmaterial with exemplary properties, which is extensivelyutilized in semiconductoraccessories manufacturing unit, ${ }^{1,2,3}$ adhesives, ${ }^{4,5}$ aerospace ${ }^{6,7,8}$ and other fields.Epoxy resins, are referred to as polyepoxides- comes under the category of reactive prepolymers.Epoxy monomer'svital feature is the oxiranering functional group, it is a three-member ring made of oxygen andtwo carbon atoms. ${ }^{9}$ The doping of other materials to enhance the strength of the epoxy resin has been a vital research field. ${ }^{10}$

\section{EXPERIMENTAL}

\section{Epoxy Resin}

The titled compound issemi-polymeric or polymeric materials or an oligomerand seldom exists in pure form. Unprocessed epoxy resins have less chemical, mechanical, heat and moisture resistance properties. These properties are enhanced by promoting the reaction of epoxy resin with propercuring agents to create a network of three-dimensional cross-linked thermoset structures. This process is referred to as curing or gelation process. Curing process of epoxy resins is an exothermic reaction and releasesthermal radiation to cause thermal degradation if not controlled.To enhance the performance of epoxy resins, even diffusion after mixing is vital. ${ }^{11}$ The polymer was purchased from M/s ROTO POLYMERS Chennai.

\section{Diethylenetriamine}

Resins linked with amine hardeners have better mechanical andthermal properties. Amine compounds are categorized as primary, secondary, and tertiary amines, in which one, two, and three hydrogen molecules of ammonia (NH3) have been replacedby hydrocarbon, respectively. Amines are once again categorized into monoamine, diamine, tri-amine, or polyamine based on the number of amines present in one

Rasayan J. Chem., 12(4), 1688-1692(2019)

http://dx.doi.org/10.31788/RJC.2019.1245384

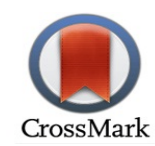


RASĀYAN J. Chem.

Vol. 12 | No. 4 |1688 - 1692| October - December | 2019

molecule andaccording to the types of hydrocarbons substituted, as aliphatic, alicyclic and aromatic amines. Curing of resins with the help of the aliphatic amines isstrong, and isexemplary in bonding nature. $^{12}$

Diethylenetriamine (abbreviated DETA) falls under the category of an organic compound with the formula $\mathrm{HN}\left(\mathrm{CH}_{2} \mathrm{CH}_{2} \mathrm{NH}_{2}\right)_{2}$.DETA is a hygroscopic liquid. This colorless liquid is soluble in water, polar organic solvents, but insoluble in hydrocarbons, with an ammonia-like odor. DETA is utilized in the chemical, pharmaceutical industry and employed as a solvent for plastics, dyes and in the chemical manufacturing unit, fabric softeners and fuel additives. DETA is used as a solvent for resins, colors, acid gases, and sulfur and as a hardener in epoxy resins. ${ }^{13}$ Boiling point is $206^{\circ} \mathrm{C}$ and its refractive index is 1.484. Diethylenetriamine was purchased from M/s SISCO RESEARCH LABORATORIES Pvt. Ltd. Navi Mumbai, India.

The curing process of Epoxy resin in Diethylenetriamineis carried out. Films are cast by the solvent evaporation method. A homogeneous mixture of epoxy resin with different concentration of curing agent is produced,utilizing magnetic stirrer Remi model. The films are produced by employing the simple technique of concentration variation of both the resin and curing agent. The concentrations of films are $2 \%, 6 \%, 16 \%$ (\% weight by weight) of DETA are prepared.

\section{Characteristic Studies}

The IR spectrum of a substance is the emplacement of the absorption bands of peculiarfunctional groups. ${ }^{14}$ The vibrational frequencies are a kind of fingerprint of the compounds. This property is used for study of organic, inorganic, polymer, smart and biological compounds. The band intensities are directly related to the concentration of the compound and hence quantitative andqualitative evaluations are possible. Spectral studies are carried out using The Perkin Elmer Spectrum Two FT-IR instrument. The utility of IR spectroscopy is possible using a Fourier transform technique. The entire region of $4000-450$ $\mathrm{cm}^{-1}$ is focused by this instrument.

Mid-infrared spectroscopy has been collectivelyutilized for the study of organic compounds,a lot of sustainable information and spectra libraries can be easily traced out. FTIR spectroscopy provides both the qualitative and quantitative dataabout the material, but its usage to epoxy systems is quite restraineddue to the positionand concentration of the oxirane ring absorptions. ${ }^{9}$

The mechanical tests are conducted by using ASTM D-638-00 using an Instron testing machine Mode15567. Mechanical tests are carried out in the laboratory at Central Leather Research Institute, Chennai.The load is increased at a uniform rate and the specimen elongates and finally ruptures.

Dielectric studies are carried out at Loyola college, Chennai. Dielectric studies are carried out at a temperature of $80^{\circ} \mathrm{C}$.

\section{RESULTS AND DISCUSSION}

\section{Spectral Analysis}

FTIR studies are carried on pure epoxy resin without curing agent, DETA and epoxy resin with varying concentration of DETA. FTIR spectrum of pure epoxy resin without curing agent is projected in Fig.-1. FTIR spectrum of DETA is shown in Fig.-2. FTIR spectra of Epoxy resin with varying concentration of DETA are shown Fig.-3. Vibrational band assignments are made.Films undergoCO $\mathrm{O}_{2}$ deformationat 555 $\mathrm{cm}^{-1}$.

Similarly, epoxy resin films with varying concentration of curing agent $2 \%, 6 \%, 16 \%$ undergo stretching vibration of C-O-C oxirane ring at $825 \mathrm{~cm}^{-1}-826 \mathrm{~cm}^{-1}$. Similarly,an epoxy resin film undergoes stretching of C-O at $1181 \mathrm{~cm}^{-1}$. Similarly, films of epoxy resin with varying concentration of curing agent $2 \%, 6 \%$, $16 \%$ undergoes $\mathrm{O}-\mathrm{H}$ deformation at $1232 \mathrm{~cm}^{-1}-1243 \mathrm{~cm}^{-1}$. Similarly, films of epoxy resin with varying concentration of curing agent $2 \%, 6 \%, 16 \%$ undergoes stretching of $\mathrm{N}-\mathrm{H}$ at $3287-3289 \mathrm{~cm}^{-1}$.

The study of relative relation of area of functional group with a concentration of curing agent is carried out. From the study, it is confirmed as an area of the functional group of FTIR spectra increases, the percentage of concentration of curing agent decreases, shown in Table-1 and Fig.-4. 
RASĀYAN J. Chem.

Vol. 12 | No. 4 |1688 - 1692| October - December | 2019

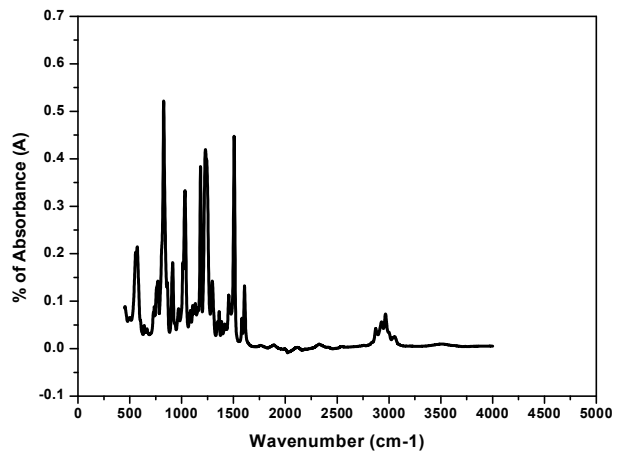

Fig.-1: FTIR Spectra of Pure Epoxy Resin

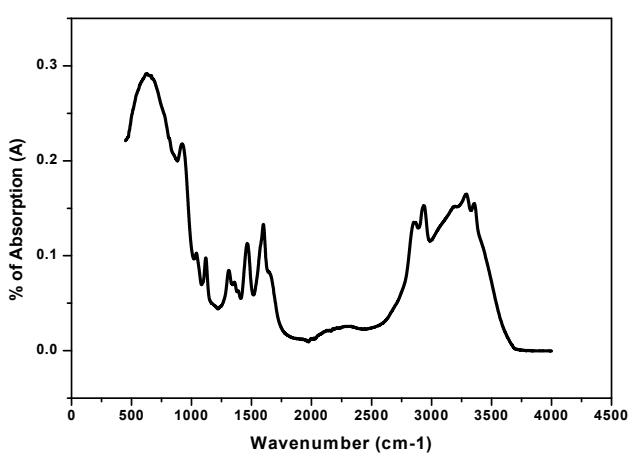

Fig.-2: FTIR Spectra of DETA

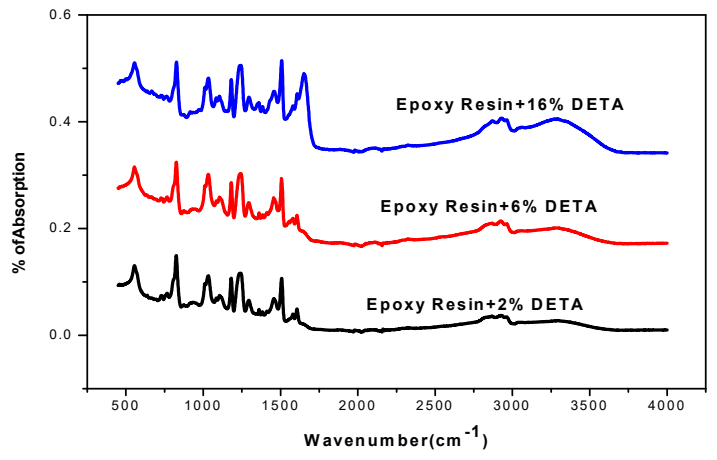

Fig.-3: FTIR Spectra of Epoxy Resin with 2\%, 6\%16\% of DETA

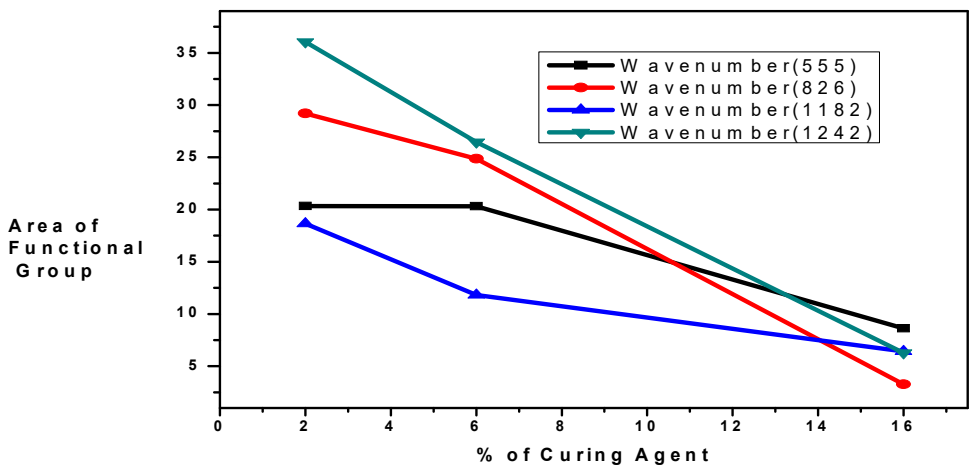

Fig.-4:Variation of Area of Functional group with Varying Concentration of Curing Agent

Table-1: Typical Variation of Area of Functional Group with Varying Concentration of Curing Agent

\begin{tabular}{c|c|c|c|c|c}
\hline S. No. & $\begin{array}{c}\text { The } \\
\text { concentration } \\
\text { of curing agent } \\
\text { in \% }\end{array}$ & $\begin{array}{c}\text { Wave } \\
\text { number(555) }\end{array}$ & $\begin{array}{c}\text { Wave number } \\
(826)\end{array}$ & $\begin{array}{c}\text { Wave number } \\
(1182)\end{array}$ & $\begin{array}{c}\text { Wave number } \\
(1242)\end{array}$ \\
\hline 1 & 2 & 20.34 & 29.20 & 18.65 & 36.05 \\
\hline 2 & 6 & 20.31 & 24.85 & 11.81 & 26.45 \\
\hline 3 & 16 & 8.62 & 3.26 & 6.41 & 6.27 \\
\hline
\end{tabular}

Mechanical studies are carried out on epoxy resin films with the changing concentrations of curing agent $2 \%, 6 \%, 16 \%$. The variation of stroke with stress is studied. It is concluded that as $\%$ of the concentration of curing agent increases the tensile strength, flexural strength, toughness also gets enhanced. Table 2 and 
RASĀYAN J. Chem.

Vol. 12 | No. 4 |1688 - 1692| October - December | 2019

figure 5 highlights the fact - \% of the concentration of curing agent increases, all the mechanical parameters such as tensile strength, flexural strength and toughness also increases. Mechanical studies are used as the tool to establish the role of curing agent is to increase the hardness of films.

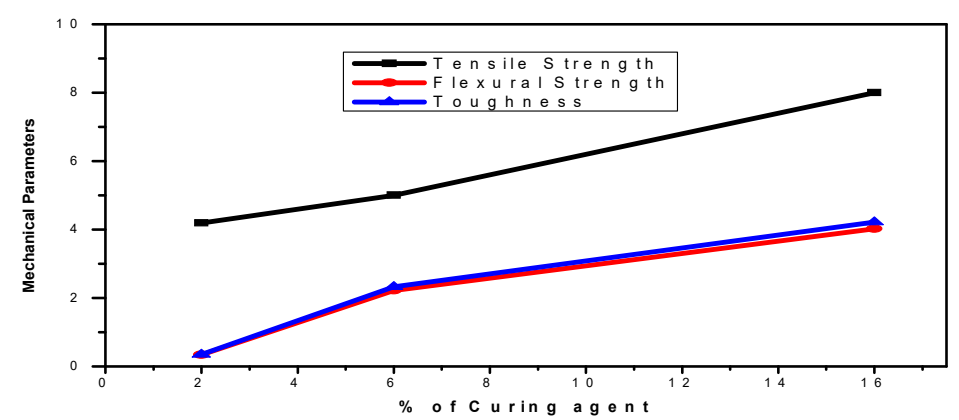

Fig.-5: Variation of Mechanical Parameters with Varying Concentrations of Curing Agent

\section{Dielectric Studies}

Dielectric studies are carried out on epoxy resin films with varying concentration of $6 \%, 16 \%$ of curing agent at temperatures $80^{\circ} \mathrm{C}$, from Fig.-6and Fig.-7it is confirmed as dielectric constant increases frequency decreases for all concentrations.

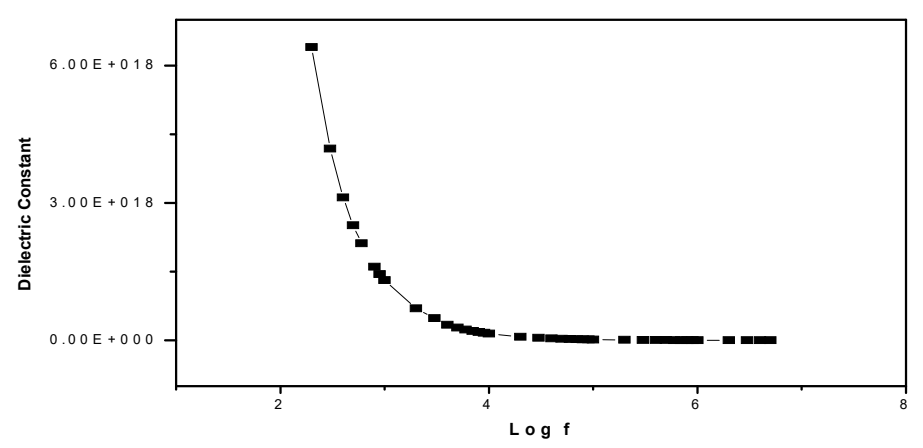

Fig.-6: Variation of Dielectric Constant with $\log f$ at Temperature $80^{\circ} \mathrm{C}$ for $16 \%$ of Curing Agent

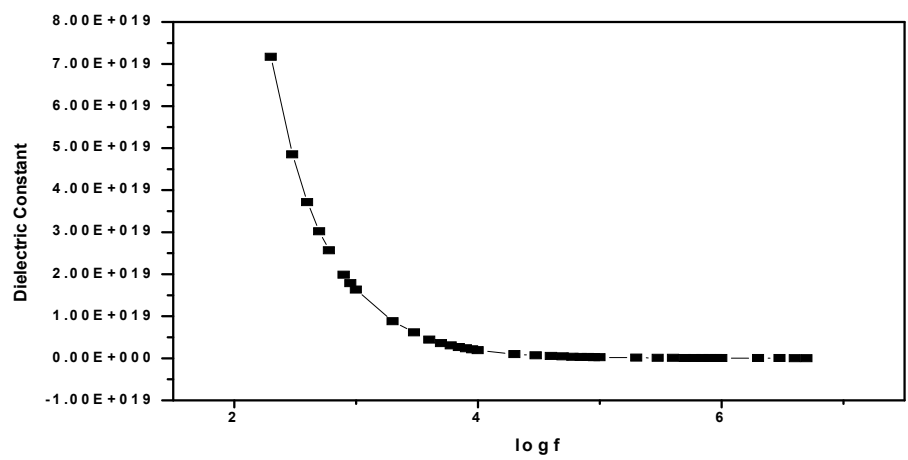

Fig.-7: Variation of Dielectric Constant with Log f at Temperature $80^{\circ} \mathrm{C}$ for $6 \%$ of Curing Agent

\section{CONCLUSION}

Both spectral analysis and mechanical studies confirm the role of curing agent. Epoxy resin film with $16 \%$ of curing agent responded well for spectroscopic and mechanical studies. A dielectric study confirms as frequency increases dielectric constant decreases. 
RASĀYAN J. Chem.

Vol. 12 | No. 4 |1688 - 1692| October - December | 2019

Table-2: Variation of Tensile Strength, Flexural Strength and Toughness with Varying Concentration of Curing

\begin{tabular}{c|c|c|c|c}
\multicolumn{5}{c}{ Agent } \\
\hline S. No. & $\begin{array}{c}\text { The } \\
\text { concentration of } \\
\text { Curing agent in } \\
\%\end{array}$ & $\begin{array}{c}\text { Tensile } \\
\text { strength } \\
\mathrm{N}\end{array}$ & $\begin{array}{c}\text { Flexural } \\
\text { Strength } \\
\mathrm{N}\end{array}$ & $\begin{array}{c}\text { Toughness } \\
\mathrm{N}\end{array}$ \\
\hline 1 & 2 & 4.19 & 0.34 & 0.35 \\
\hline 2 & 6 & 5.00 & 2.22 & 2.33 \\
\hline 3 & 16 & 8.00 & 4.02 & 4.22 \\
\hline
\end{tabular}

\section{REFERENCES}

1. K. Kayaba, A. Tabata, T. Otsu, Y. Tsuji, A. Oura, Epoxy resin compositions and semiconductor devices, US20050090044A1 U.S. Patent (2005 Apr 28).

2. S. Honda, Y. Sawamura, M. Tanaka, K. Kayaba, T. Teshiba, Semiconductor device-encapsulating epoxy resin composition. US5360837A. U.S. Patent (1994 Nov 1).

3. M. G. Kim, S. Han, H. S. Cheon, Epoxy Resin Composition for Encapsulating Semiconductor Device and Semiconductor Device Encapsulated Using the Same, US20140179834A1. U.S. Patent (2014 Apr 26).

4. F. Lapique, K. Redford, Int. J. Adhes. Adhes., 22, 337(2002), DOI: 10.1016/S0143-7496(02)00013-1

5. R. Furuno, Y. Takatuji, K. Kubo, T. Haruyama, Electr. Commun. Jpn. ,100, 67(2017), DOI: 10.1002/ecj.11924

6. M. Abdullah, F. Gholamian, A. R. Zarei, ISRN Aerosp. Eng., (2013), DOI: 10.1155/2013/679710

7. A. Toldy, B. Szolnoki, G. Marosi, Polym. Degrad. Stab., 96, 371(2011), DOI: 10.1016/j.polymdegradstab.2010.03.021

8. A. Terenzi, M. Natali, R. Petrucci, M. Rallini, L. Peponi, M. Beaumont, A. Eletskii, A. Knizhnik, B. Potapkin, J. M. Kenny, Polymer Composites, 38, 105(2017), DOI: 10.1002/pc.23565

9. María González González, Juan Carlos Cabanelas and Juan Baselga, Materials Science, Engineering and Technology, 261(2012).

10. Zhen Ge , Wenguo Zhang, Chao Huang and Yunjun Luo, Materials,11(6), 932(2018), DOI: 10.3390/ma1 1060932

11. Shuichiro Yoshida, Polymer Journal , 46, 430(2014), DOI: 10.1038/pj.2014.15

12. Najuma Abdul Razack, LityAlen Varghese, International Journal of Engineering Research \& Technology, 3(1), 2662 (2014).

13. Health Council of the Netherlands Committee on Updating of Occupational Exposure Limits, a committee of the 2,2'-Iminodi(ethylamine) Health-based Reassessment of Administrative Occupational Exposure Limits( 2005).

14. Bright A., T. S. Renuga Devi and S. Gunasekaran, International Journal of ChemTech Research, 2(1), 379(2010).

[RJC-5384/2019] 